\title{
It Is Possible to Classify Non-erosive Reflux Disease (NERD) Patients into Endoscopically Normal Groups and Minimal Change Groups by Subjective Symptoms and Responsiveness to Rabeprazole-A Report from a Study with Japanese Patients
}

Motoyasu Kusano $\cdot$ Naohito Shirai · Kanako Yamaguchi · Yasuyuki Shimoyama $\cdot$ Michio Hongo $\cdot$ Tsutomu Chiba $\cdot$ Yoshikazu Kinoshita · The Acid-Related Symptom (ARS) Research Group

Published online: 2 December 2008

(C) Springer Science+Business Media, LLC 2008

\section{Erratum to: Dig Dis Sci}

DOI 10.1007/s10620-008-0290-2

This article was published with an incomplete author listing-Yasuyuki Shimoyama was left out. This erratum includes the name and affiliation of the missing author.

The online version of the original article can be found under doi: 10.1007/s10620-008-0290-2.

M. Kusano $(\varangle) \cdot$ Y. Shimoyama

Department of Endoscopy and Endoscopic Surgery, Gunma University Hospital, 3-39-15 Showamachi, Maebashi, Gunma

371-8511, Japan

e-mail: mkusano@showa.gunma-u.ac.jp

N. Shirai

Department of Gastroenterology, Enshu Hospital,

Hamamatsu, Japan

\section{K. Yamaguchi}

Department of Internal Medicine, Saga Medical School,

Saga, Japan

M. Hongo

Departments of Comprehensive Medicine and Psychosomatic

Medicine, Tohoku University Hospital, Sendai, Japan

T. Chiba

Department of Gastroenterology and Hepatology, Kyoto

University Graduate School of Medicine, Kyoto, Japan

\section{Y. Kinoshita}

Department of Gastroenterology and Hepatology, Shimane

University School of Medicine, Izumo, Japan

The Acid-Related Symptom (ARS) Research Group

Izumo, Japan 